population aged $=65$, the prevalence of a positive IGRA result was between $18 \%$ and $37 \%(95 \% \mathrm{CI})$.

Conclusions IGRA positivity was found to be lowest in the white British population compared with other ethnic groups. Interestingly, of the UK indigenous white elderly population almost $1 / 3$ are infected with TB (latent or active) highlighting significant disease burden among older age groups. With IGRAs heralded as the more specific and reliable diagnostic test, such results may aid future planning and policy making for the management of TB in the UK.

\section{P17 CLINICAL UTILITY OF THE TUBERCULOSIS INTERFERON GAMMA TEST (IGT) IN A LOW INCIDENCE AREA}

doi:10.1136/thoraxjnl-2011-201054c.17

J T Donovan, A Yogendran, I D Ramsay, C Giles, R W Lee, A T Scourfield, S R Doffman. Department of Respiratory Medicine, Brighton and Sussex University Hospitals NHS Trust, Brighton, UK

Introduction The clinical utility and cost effectiveness of IGT in low prevalence areas of TB remains unclear. In some clinical settings it has been used to exclude active disease. We describe the experience of IGT in a teaching hospital in a low prevalence area (13/100 000). Methods We identified individuals who had undergone IGT for any indication from 01 January 2010 to 30 June 2011. Case notes and electronic records were reviewed retrospectively to identify baseline demographics, indications for testing and outcomes where a positive result was identified. Healthcare workers, contacts of $\mathrm{TB}$ and new entrants were all screened for latent TB infection (LTBI) with tuberculin skin test and if positive, IGT (as per NICE, 2006). Those on immunosuppressant therapy had IGT alone if a risk factor was identified. In May 2011, there was a change in local contract from QuantiFERON $^{\circledR}$ TB-Gold In-Tube (OFT), Cellestis International, Australia to T Spot-TB ${ }^{\circledR}$ (TSp) Oxford Immunotec, Abingdon, UK. Results 179 cases were identified, 75 (42\%) cases had TSp performed and $104(58 \%)$ cases with OFT. There were $5(3 \%)$ indeterminate results (OFT: 4 [4\%]; T Spot-TB: 1 [1\%]). Two TSp tests could not be processed as there were insufficient white cells (both haematooncology patients). Median age was 40 years (IOR 25-60), the majority were from Europe 135 (75\%). Other ethnicities included African 17 (9\%), South East Asian 14 (8\%), Western Pacific 5 (3\%), Eastern Mediterranean 4 (2\%) and the Americas 4 (2\%). 108 (60\%) cases were performed to exclude latent TB infection and $71(40 \%)$ to exclude active TB (see Abstract P17 table 1).

\section{Abstract P17 Table 1}

\begin{tabular}{lllll}
\hline & $\begin{array}{l}\text { Number } \\
(\mathbf{n = 1 7 9})\end{array}$ & $\begin{array}{l}\text { No. +ve IGRA } \\
(\mathbf{n}=\mathbf{3 2}) \\
(\% \text { of group) }\end{array}$ & $\begin{array}{l}\text { Treated latent/ } \\
\text { active TB (n=21) } \\
\text { (\% of positive IGRA) }\end{array}$ \\
\hline $\begin{array}{lllll}\text { Latent TB } \\
(\mathbf{n}=108)\end{array}$ & $\begin{array}{l}\text { Pre-Anti TNF therapy } \\
\text { Contact screening }\end{array}$ & 45 & $1(2 \%)$ & $1(100 \%)$ \\
& Healthcare worker & 29 & $11(38 \%)$ & $5(45 \%)$ \\
& screening & $6(26 \%)$ & $4(75 \%)$ \\
& New entrant & 11 & $4(36 \%)$ & $2(50 \%)$ \\
$\begin{array}{l}\text { To exclude } \\
\text { active TB } \\
(\mathbf{n}=71)\end{array}$ & $\begin{array}{l}\text { Fever, lymphadenopathy } \\
\text { or systemically unwell }\end{array}$ & 43 & $7(16 \%)$ & $6(86 \%)$ \\
& Uveitis/choroiditis & 15 & $3(20 \%)$ & $2(66 \%)$ \\
& HIV infection & 2 & $0(0 \%)$ & $0(0 \%)$
\end{tabular}

Conclusions In a low incidence population, approximately one third of new UK entrants, contacts and health-care workers were diagnosed with latent TB, $56 \%$ of whom received chemoprophylaxis. The role of IGT to screen for active disease is unclear and requires further investigation. However, it may be of use in patients with uveitis/choroiditis. In those patients with a positive IGT, $80 \%$ went on to receive standard therapy for active $\mathrm{TB}$, all of whom clinically improved. However, screening for LTBI was less cost effective for those undergoing biological therapy with only one positive (2\%) result.

\section{P18 HOW EFFECTIVE IS THE RECOMMENDED STAGING FOR LATENT TB FOLLOW-UP?}

doi:10.1136/thoraxjnl-2011-201054c.18

D Thomas, M Jarvis, A Williams. Royal Bournemouth Hospital, Bournemouth, UK

Introduction NICE (2011) recommends that patients with latent TB infection who are eligible for but decline treatment are followed up with a chest x-ray (CXR) at 3 and 12 month intervals to assess for $\mathrm{TB}$ reactivation. The aim of this study was to assess the effectiveness of this strategy in detecting reactivation of $\mathrm{TB}$.

\section{Method}

- A retrospective case note analysis of 146 latent TB patients (2006-2011) of all ages.

- Mode age range 16-35 (46\%).

- Follow-up attendance, clinical presentation, CXR appearances and patient demographics were recorded.

\section{Results}

- 47\% (n=69) attended for follow-up at 3 and 12 months.

- 18\% DNA at 3 months, 35\% DNA at 12 months. 13\% moved away.

- $98.6 \%$ of patients showed no evidence of TB reactivation in a 12 -month period.

- $52 \%$ of patients were under 35 .

- $2(1.4 \%)$ patients developed active TB within a 12-month period. One was found to have CXR changes at the 3-month follow-up, and was later admitted with TB meningitis. The other was symptomatic (no CXR changes) and was treated empirically for active TB.

- $63 \%$ were new entrants; $41 \%$ had been in the UK $<1$ year.

- 1 patient was immunosuppressed.

- Common risk factors for LTBI were ethnicity (73\%) and occupational exposure (19\%). Only 12\% recalled previous TB contact.

Discussion

- 3 and 12-month follow-up had a very low yield of detecting TB reactivation in this sample $(1.4 \%)$.

- It cost $£ 16000$ (based on current PbR tariff) to screen the 69 patients who attended at 3 and 12 months.

- Use of limited resources must be justified. Are there better staging intervals for follow-up?

- Follow-up is also associated with a high DNA rate, particularly at 12 months, further stretching resources.

- However, follow-up allows health promotion regarding TB symptoms and the role of chemoprophylaxis.

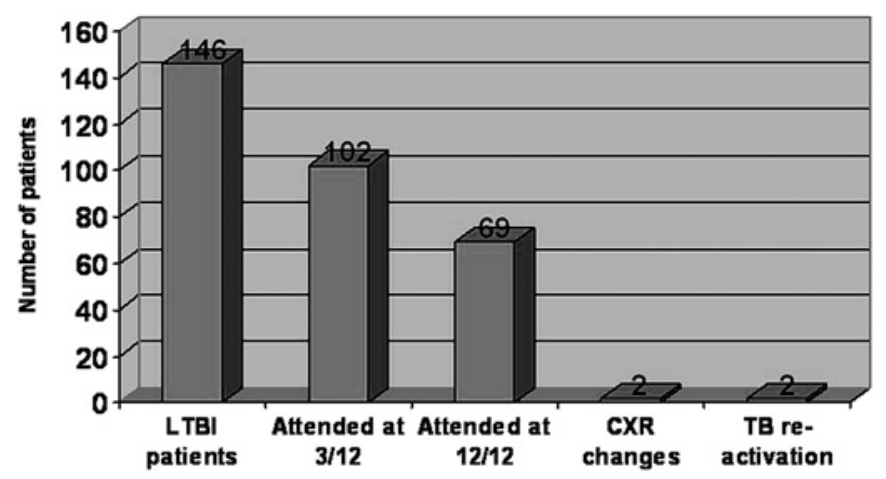

Abstract P18 Figure 1 Effectiveness of latent TB follow-up. 